Article

\title{
Nanostructured Cobalt Obtained by Combining Bottom-Up and Top-Down Approach
}

\author{
Marcello Cabibbo \\ DIISM/Università Politecnica delle Marche, 60131 Ancona, Italy; m.cabibbo@staff.univpm.it; \\ Tel.: +39-071-220-4728
}

Received: 10 October 2018; Accepted: 16 November 2018; Published: 18 November 2018

\begin{abstract}
Nanostructured metallic materials can be obtained by two major processing strategies: a bottom-up approach that starts with powdered metals to be mechanically and chemically compacted via different compaction methodologies, and a top-down approach that starts with bulk conventional metallic materials that are induced to a sometimes-extraordinary grain size reduction via different severe plastic deformation (SPD) methods. In the present study, a dual strategy was followed to obtain a sound and stable nanostructured commercially pure cobalt. Powdered cobalt of $2 \mu \mathrm{m}$ was compacted by ball-milling (BM) followed by spark-plasma sintering (SPS) to obtain a bulk metallic material whose relative mass density reached a value of $95.8 \%$. This process constituted a bottom-up strategy to obtain ultrafine submicrometer-grained bulk cobalt, and a top-down strategy of subjecting the BM + SPS submicrometer-grained cobalt to a specific SPD technique, namely equal-channel angular pressing (ECAP). The latter was carried out in one to four passes following so-called route $\mathrm{B}_{\mathrm{C}}$, reaching $98.4 \%$ density and a nanometric-grained microstructure. The material was microstructurally and mechanically characterized by TEM (transmission electron microscope) and nanoindentation. The obtained results are a representative solid example for obtaining nanostructured metallic materials using both grain-refining strategies, bottom-up and top-down.
\end{abstract}

Keywords: ball-milling; spark-plasma sintering; equal-channel angular pressing; nanoindentation; TEM; cobalt; nanocrystalline metal

\section{Introduction}

In the mid-1980s, Gleiter [1] made the visionary argument that metals and alloys, in their nanocrystalline (NC) form, would have several appealing mechanical characteristics of potential significance for structural applications. Since then, NC metals and alloys, with grain sizes typically smaller than $100 \mathrm{~nm}$, have been the subject of considerable research activity worldwide. In fact, these materials have shown quite interesting mechanical properties, such as high strength, increased environmental resistance, improved strength and/or ductility with increasing strain rate, and, in some cases, superplastic deformation [2].

In this regard, in the past few decades, to produce ultrafine-grained (UFG) and NC materials, two methodologies emerged and evolved [3]: bottom-up and top-down. In the bottom-up method, ultrafine powders are synthesized via various techniques and then compacted into bulk form, using ways similar to those applied in conventional powder metallurgy (PM) [4]. The top-down process is based on severe plastic deformation (SPD) methods such as high-energy ball-milling (BM) [4], equal-channel angular pressing (ECAP) [5], high-pressure torsion (HPT) [6], accumulative roll-bonding (ARB) [7], surface mechanical attrition treatment (SMAT) [8], and dynamic severe plastic deformation (DSPD) [9]. The bottom-up strategy is based on either a one-step processing method such as electrodeposition (ED), which in most cases leads to porosity-free samples [10], or two-step processing, in which particle synthesis is followed by consolidation. The bottom-up processed UFG and NC materials have 
much higher strengths than their coarse-grained counterparts, usually at the expense of ductility [11]. To avoid such complications, in the top-down methodology, a bulk material composed of coarse grains that are progressively refined to UFG and NC regimes constitutes the starting condition. Since no powder synthesis is involved, this process is also called a one-step process, even though accumulative passes (or steps) are often needed to achieve the desired grain size levels.

In the bottom-up process, to obtain sound nanostructured materials, the consolidation must fulfill two conditions: (i) mean grain size needs to be at least submicrometer (UFG) [11], and (ii) porosity should be controlled according to the sought-after property.

Bulk nanostructured Co is becoming a promising class of biomaterials due to the unusual physical and mechanical properties compared to conventional coarse-grained counterparts. In particular, due to its high strength, wear resistance, and corrosion resistance, cobalt (and its alloys) is known to have great potentials as dental prostheses and orthopedic implants, to name few typical applications. For this reason, techniques and sequence of processes able to produce nanostructured Co are of great scientific and technologic interest.

Extensive efforts have been devoted to the making of nanostructured Co by either a top-down or bottom-up strategy [12]; the factors governing the grain-refining process are related to the synthesis method. In this respect, various methods have been reported for the production of UFG and NC materials ([13] and references therein).

As for the top-down method, one of the major drawbacks of using SPD techniques such as HPT on cobalt is that cobalt exists in two allotropic forms: a low-temperature hcp and a high-temperature fcc phase. It has been reported that when the crystallite size decreases, formation of the fcc-Co phase is favored. Previous studies revealed that fcc-Co is the most stable phase for crystallite sizes below $20 \mathrm{~nm}$, while between 20 and $40 \mathrm{~nm}$, both hcp and fcc phases are present. For crystallites larger than $40 \mathrm{~nm}$, the hcp phase is stabilized [14]. It is thus now well established that the factors behind the enhanced properties of nanostructured materials are size-sensitive.

Among the various SPD techniques, ECAP can give grain sizes typically in the UFG range and beyond [15-21]. In particular, ECAP is an especially attractive processing method because it allows large bulk samples to be produced that are free from any residual porosity and are subjected to small shape changes. The evolution of the microstructure during ECAP is closely driven by the specific pressing conditions, i.e., by the shearing deformation induced in the material at each pass through the die $[15,16]$. Plastic deformation of metals occurs as a result of the formation, movement, and storage of dislocations. In fact, microstructure evolution during ECAP is directly linked to a complex dislocation evolution into networks and to dislocation recombination and annihilation phenomena. During shearing deformation, the evolution and accumulation of misorientations across both low-angle boundaries (LABs) and high-angle boundaries (HABs) are closely related to the crystallographic accommodation of each crystallite with its neighboring crystallites. In deformation route $\mathrm{B}_{\mathrm{C}}$, a rotation of $+90^{\circ}$ per pass is induced, and a full cycle of shear deformation, occurring at given crystallographic dislocation glide planes, is completed after four consecutive passes.

The present study was aimed at obtaining a nanostructured commercially pure cobalt by using both strategies: the bottom-up, namely BM + SPS, followed by the top-down, namely ECAP. To this end, the BM + SPS compacted and then ECAP cobalt needs to fulfill both of the following conditions: (i) grain size generated by the BM + SPS compaction process should possibly be kept within a submicrometer level, and (ii) the compacted cobalt porosity should reach a sufficient level to meet the typical properties of bulk commercially pure metals, and this has to be at least maintained, if not even reduced, after ECAP. In-depth process control of the UFG and, eventually, NC nature and of the relative densification of the compacted cobalt powder is an essential requirement for potential industrial application of the bulk Co produced by means of this approach. 


\section{Materials and Methods}

A commercially pure cobalt with initial average particle size of $2 \mu \mathrm{m}$ was used. The bottom-up refining approach consisted of BM + SPS, that is, a 2-step process in which the micrometer cobalt powders were milled and then sintered to obtain a UFG structure. The top-down process consisted of further refining the bulk compacted cobalt to reach an NC structure by ECAP.

The BM was performed by using batches of $5 \mathrm{~g}$ that were introduced into a hardened steel cylindrical reactor together with stainless steel balls. The batches were subjected to BM at room temperature in an argon environment for a duration of $12 \mathrm{~h}$. Then, the ball-milled Co powder was directly fed to the SPS chamber and consolidated at a temperature of $300^{\circ} \mathrm{C}$ for $1 \mathrm{~h}$ under a constant load of $\sim 1 \mathrm{GPa}$. To prevent oxidation of the samples, the process was performed at a vacuum level of $2 \times 10^{-6} \mathrm{~Pa}$. An SPS Syntex ${ }^{\odot}$ model $515-\mathrm{S}^{\circledR}$ was used. The sintering process involved batches of $2.5 \mathrm{~g}$ of BM Co loaded into a cylindrical graphite matrix whose inner diameter was $10 \mathrm{~mm}$, and then placed between 2 electrodes under an argon environment. During SPS processing, heating was applied by pulsed direct-current through the uniaxial pressurized die assembly. The DC cycle was set at 18 pulses on and 3 pulses off, for $5 \mathrm{~ms}$ each. The sintering process proceeded under a $50 \mathrm{MPa}$ load, with heating and cooling cycles of $100{ }^{\circ} \mathrm{C} / \mathrm{min}$, final sintering temperature of $500{ }^{\circ} \mathrm{C}$, and a dwelling time of $180 \mathrm{~s}$, maintaining total time for the SPS process within $20 \mathrm{~min}$ per sample. Samples produced by the bottom-up process were cylindrical, with a diameter of $10 \mathrm{~mm}$ and height of $30 \mathrm{~mm}$.

The density of as-compacted cylinder was measured by Archimedes method (ASTM B962-15, 2015), by immersion in ortho-xylene, and by averaging three different measurements.

The top-down refining process was performed using ECAP. The ECAP die consisted of 2 blocks of SK3 tool steel (Fe-1.1\% C), which were bolted together to give an L-shaped channel with a circular cross-section $10 \mathrm{~mm}$ in diameter, consisting of 2 linear parts intersecting at an angle $\Phi=90^{\circ}$ with a curvature extending over an angle $\Psi=20^{\circ}$. With this die configuration, a true strain of $\varepsilon=1.08$ was imposed on the specimens at each pass $[15,16,18,21]$. Cylindrical bars were pressed at $500 \mathrm{~K}$ into the ECAP die with forces ranging from $40-80 \mathrm{kN}$ and a pressing speed ranging from $20-40 \mathrm{~mm} / \mathrm{min}$, from 1 to 4 passes. Route $B_{C}$ was used, and this involves a rotation of $+90^{\circ}$ per pass, with a full cycle of rotation completed after 4 passes $[15,16,20,21]$. 10 cylindrical samples were produced by BM + SPS, and these were used to carry out the ECAP passes through route $\mathrm{B}_{\mathrm{C}}$. Thus, at least one billet was obtained per each ECAP pass, from 1 to 4 .

The hardness, $H$, and local elastic modulus, $E_{\mathrm{r}}$, were measured using the nanoindentation technique with a Hysitron $\odot$ Ubi- $1{ }^{\circledR}$ triboscope nanoindenter (Minneapolis, MN, USA). Uniaxial compression was performed using a 3-sided pyramidal Berkovich tip with edge aperture angle of $65.35^{\circ}$ and tip curvature radius of $120 \mathrm{~nm}$. The nanoindentation measurements were analyzed using the Oliver and Pharr method [22,23]. $H$ and $E_{\mathrm{r}}$ were obtained after a complete cycle of loading-unloading procedure. The unloading curve was fitted with the power-law relationship $P=B\left(h-h_{\mathrm{f}}\right)^{k}$, where $P$ is the tip load, $h$ the displacement, $h_{\mathrm{f}}$ the displacement after unloading, $B$ and $k$ the fitting parameters. The penetration contact depth, $h_{c}$, can be estimated by $h_{c}=h_{\max }-\eta\left(P_{\max } / S\right)$, where $h_{\max }$ is the maximum indenter penetration depth at the peak load, $P_{\max }, \eta$ is a tip-dependent constant, and $S$ the material stiffness. For a Berkovich tip, $\eta=0.75$. Calibration was carried out on fused quartz $\left(E_{\mathrm{r}}=72 \mathrm{GPa}\right)$ according to the specifications and recommendations resulting from a round robin experiment recently published by Cabibbo et al. [24]. A trapezoidal load function consisting of equal load and unload rates to the peak load $P_{\max }$ was used.

Thin foils $\sim 90 \mu \mathrm{m}$ thick were prepared by conventional mechanical grinding and polishing techniques. Foils were then punched to $3 \mathrm{~mm}$ TEM discs and double-side dimpled for the ion-milling final preparation. To produce transparent TEM discs, a Gatan $\odot$ PIPS (Pleasanton, CA, USA) was used, with an ion beam energy of $4 \mathrm{kV}$ with incident angles of 8,6 , and $4^{\circ}$ for the first half, the second quarter, and the final quarter of the preparation stage, respectively. Microstructure inspections were carried out by means of a Philips $\odot \mathrm{CM}-20^{\circledR}$ TEM (Eindhoven, The Netherlands) operated at $200 \mathrm{keV}$ equipped with a nitrogen-cooled double-tilt specimen holder. 
Mean grain size was measured by a standard stereology ASTM-E112 linear intercept method over more than 15 micrographs and more than 80 grains, per experimental conditions.

The formation of the hcp phase, other than the expected fcc-Co phase, was determined by X-ray powder diffraction (XRD) using a Siemens D5000 diffractometer (Munich, Germany) equipped with a double cradle and working at $\omega \sim 5^{\circ}$, with a pattern $(2 \theta)$ ranging between $40^{\circ}$ and $120^{\circ}$. A Co K $\alpha 1$ source was used.

All the inspections were carried out along the X-plane according to the usual notation of the different shearing planes in ECAP straining $[15,21]$. This is the plane normal to the isostatic pressure direction in the SPS process, and normal to the pressing direction in the ECAP.

\section{Results and Discussion}

The initial cobalt powder was reasonably uniform with a mean size of $2.1 \mu \mathrm{m}$, as shown in Figure 1. The first stage of grain refining, that is, BM + SPS, reduced the initial $\sim 2 \mu \mathrm{m}$ Co powder down to $480 \pm 80 \mathrm{~nm}$, that is, to a submicrometer level. The grained structure was then further refined by ECAP to $60 \pm 10 \mathrm{~nm}$ after ECAP-B $\mathrm{B}_{C} / 1$, and finally to $25 \pm 5 \mathrm{~nm}$ after ECAP-B $/ 4$, with a corresponding final relative mass density of $98.7 \%$. Figure 2 shows the grain-refining trend with the initial bottom-up process and the second top-down ECAP from 1-4 via route $\mathrm{B}_{\mathrm{C}}$. The obtained NC grains after $E C A P-B_{C} / 4$ were also consistent with grain sizes in [25], where a Co average grain size of $35 \mathrm{~nm}$ with a sufficiently narrow distribution was reported. The grain size distributions obtained after the different refining stages are reported in the Figure 2 inset. These show quite a narrow grain size distribution after the ECAP cumulative shearing process.

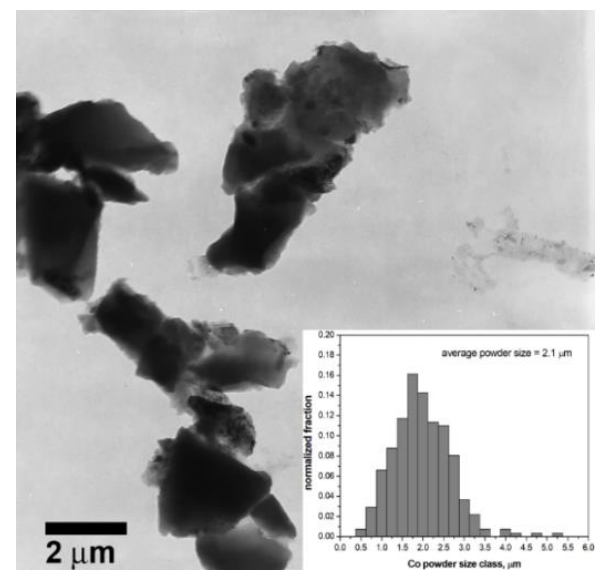

Figure 1. TEM (transmission electron microscope) extraction image showing the cobalt starting powder dimension; inset shows the powder size distribution obtained from 350 measurements performed on TEM.

Correspondingly, the microstructure was subjected to significant modifications, which are reported in Figure 3. In particular, the bottom-up BM + SPS process induced satisfactory compaction of the bulk cobalt, reaching a specific density value of $95.8 \%$ (Figure $3 a$ ). The following ECAP-B $\mathrm{B}_{C} / 4$ process reduced to some extent the bulk compaction to a maximum level of $98.4 \%$ specific density (that is, to a minimum porosity level of $1.6 \%$ ). 


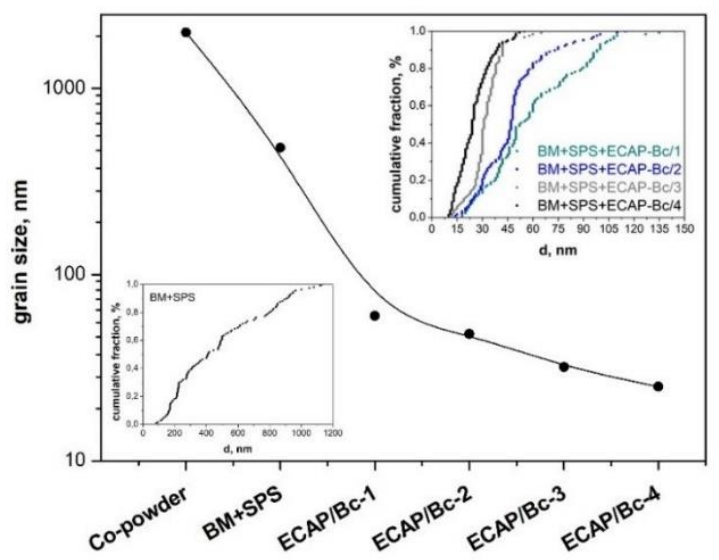

Figure 2. Grain size vs. deformation processes, i.e., ball-milling (BM) + spark-plasma sintering (SPS) (bottom-up process) and BM + SPS + equal-channel angular pressing (ECAP)- $\mathrm{B}_{\mathrm{C}} / 1-4$ (top-down process). Insets report the grain size distribution of the bottom-up BM + SPS (left-hand side) and the bottom-up + top-down BM + SPS + ECAP-B $/ 1-4$ (right-hand side).
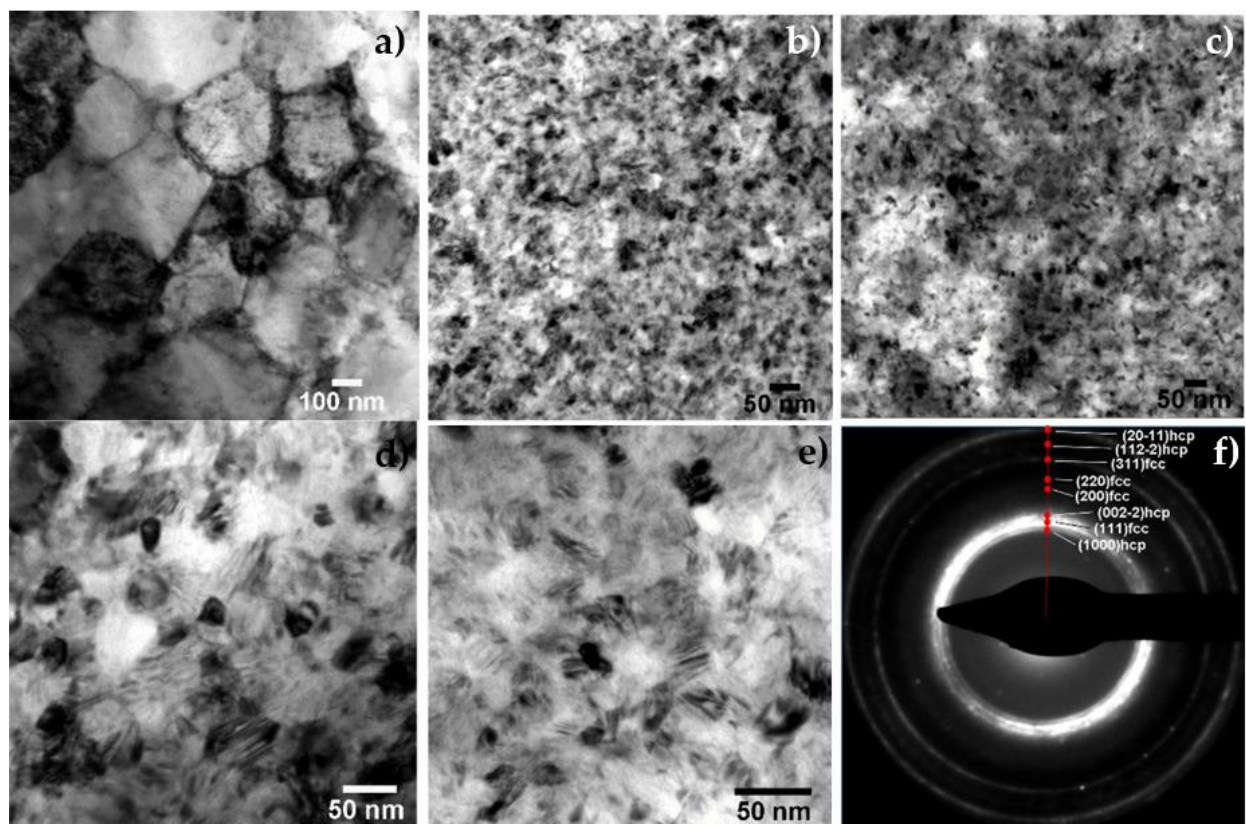

Figure 3. Representative TEM micrographs of ultrafine-grained cobalt obtained by (a) BM + SPS, (b) $\mathrm{BM}+\mathrm{SPS}+\mathrm{ECAP}-\mathrm{B}_{\mathrm{C}} / 1$, (c) $\mathrm{BM}+\mathrm{SPS}+\mathrm{ECAP}_{-\mathrm{B}} / 2$, (d) $\mathrm{BM}+\mathrm{SPS}+\mathrm{ECAP}-\mathrm{B}_{\mathrm{C}} / 3$, and (e) $\mathrm{BM}+\mathrm{SPS}$ + ECAP-B ${ }_{C} / 4$. (f) SAEDP rings (aperture size $80 \mathrm{~nm}$ ) refer to the $\mathrm{BM}+\mathrm{SPS}+\mathrm{ECAP}-\mathrm{B}_{\mathrm{C}} / 1$ condition.

In the case of cobalt produced by PM, such as the BM process, the residual porosity after consolidation is known to be the main factor governing the microstructural and mechanical characteristics of the nanostructured consolidated material $[25,26]$. On the other hand, in UFG Co, the mechanical properties are also affected by the fcc-hcp interphase boundaries within the lamellar structure [25-27]. In [27], cobalt powders were processed by a combination of two different techniques of plastic deformation, BM and HPT, and the structure consisted of a two-phase mixture of hcp + fcc, with large amounts of stacking faults, especially of twin type. In fact, a certain amount of metastable fcc phase is always observed in the NC microstructure at room temperature regardless of the applied process [25-27]. Since hcp and fcc are both close-packed structures, stacking faults usually play a key role in all the models describing the transformation, when it is either thermally activated or induced by a cold work process [28]. 
In the present study, it appeared that ECAP straining induced a phase rearrangement between the existing fcc and hcp phases. In fact, as reported in Figure 3b-e, TEM inspections showed a lamellar substructure with a high density of nanotwins and stacking faults, which is consistent with the low stacking-fault energy of Co [29]. A highly faulted microstructure, composed of a high concentration of stacking faults/twins, was observed in particular after three and four ECAP-BC passes; these are consistent with the low stacking-fault energy of cobalt.

Thus, in addition to grain boundary strengthening, other hardening mechanisms act simultaneously during plastic deformation. The role of twins can play a role similar to grain boundaries during work-hardening of metals with low stacking-fault energy (such as Co), as suggested by Kalidindi [30]. This microstructure mechanism was studied from both a theoretical [31] and an experimental [32] point of view. However, in polycrystals where grain and twin boundaries coexist, grain boundaries still constitute stronger barriers for dislocation motion than twin boundaries. This is because dislocations can dissociate and penetrate relatively easily into the twinned region, whereas at grain boundaries, significant pile-up of dislocations is required before slip in neighboring grains is activated [32].

A nanoindentation test was carried out to determine local elastic modulus, $E_{\mathrm{r}}$, and hardness, $H$, of the bulk UFG and NC Co sample obtained by BM + SPS and BM + SPS followed by ECAP-B $/ 1-4$, respectively. Figure 4 shows a plot of $H$ and $E_{\mathrm{r}}$ in the bottom-up and top-down processes.

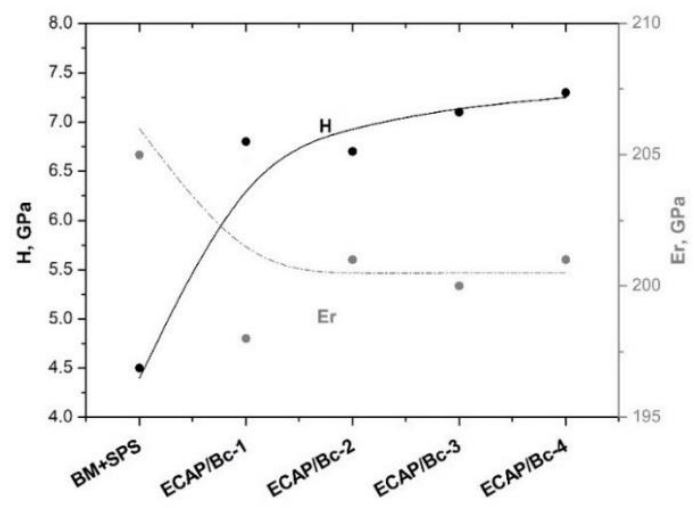

Figure 4. Nanoindentation hardness, $H$, and reduced elastic modulus, $E_{\mathrm{r}}$, vs. BM + SPS, and vs. cumulative ECAP-B $\mathrm{B}_{\mathrm{C}}$ straining, after BM + SPS.

The hardness rose by more than $30 \%$ from the bottom-up, to the first ECAP pass, while it remained essentially unchanged with the following cumulative ECAP straining. The enhanced mechanical properties obtained after ECAP are likely to be explained as a combined role of fcc-hcp structures and the presence of both stacking faults and nanotwins. Correspondingly, the local elastic modulus reduced slightly from 205 to 198 GPa from the bottom-up to the first ECAP pass, and it also remained unchanged with the ECAP cumulative strain. The obtained mechanical data are in good agreement with previously published results. In [33] the measured hardness and elastic modulus were $\sim 7.3 \mathrm{GPa}$ and $\sim 210 \mathrm{GPa}$, respectively. Similar results were reported in [27] $(H=4.7-7.5 \mathrm{GPa})$, [34] $(H=2.5-4.5 \mathrm{GPa})$, and [35] $\left(E_{\mathrm{r}}=180-220 \mathrm{GPa}\right)$ for similar bottom-up and SPD deformation techniques. On the other hand, in [35], NC cobalt was reported to have yield and tensile strengths about two to three times higher than those of non-UFG polycrystalline cobalt, while the elastic modulus for both materials was approximately the same.

Finally, the correlation between grain size reduction and nanoindentation $H$ with cumulative straining was inspected, and results are reported in the plot of Figure 5. Results show that the Hall-Petch relationship can be considered validated throughout the UFG and NC grain size ranges that were obtained by both BM + SPS and following ECAP-B $/ 1-4$, that is, down to 25 nm (obtained at $\left.\mathrm{BM}+\mathrm{SPS}+\mathrm{ECAP}-\mathrm{B}_{\mathrm{C}} / 4\right)$. 


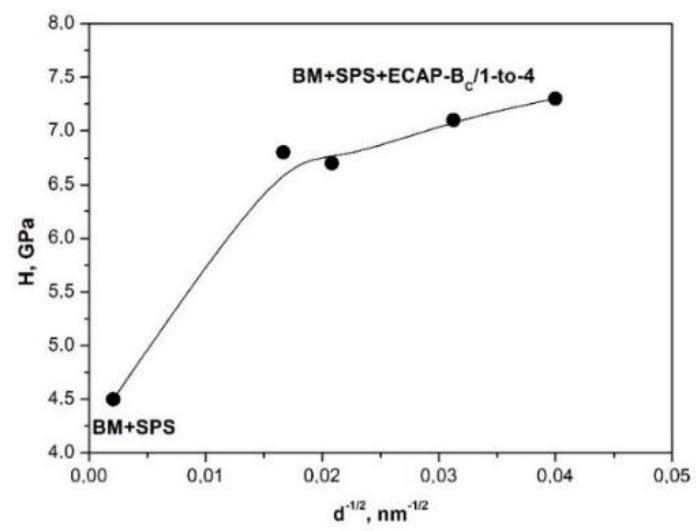

Figure 5. Hardness, $H$, vs. mean grain size, $d^{-1 / 2}$, for BM + SPS (bottom-up process) and BM + SPS + ECAP-B $\mathrm{C} / 1-4$ (top-down process).

On the other hand, the local elastic modulus, $E_{\mathrm{r}}$, did not depend on the grain size reduction induced by the top-down ECAP process. In fact, $E_{\mathrm{r}}$ reduced by $3 \%$ from BM + SPS to the first ECAP pass and did not further reduce with cumulative ECAP straining, as shown in Figure 4.

It turns out that compared to the significant $H$ rise from $\mathrm{BM}+\mathrm{SPS}$ to ECAP- $\mathrm{B}_{\mathrm{C}} / 1$ and then up to $\mathrm{ECAP}-\mathrm{B}_{\mathrm{C}} / 4$ of up to $50 \%$ and then a final $62 \%$, the local elastic modulus $E_{\mathrm{r}}$ variation with grain size reduction was rather modest. The virtual insensitivity of the Co elastic modulus with grain size reduction (from UFG, of BM + SPS, to NC, after ECAP-B $\mathrm{B}_{\mathrm{C}}$ /4) can be explained from a microstructure point of view. The Co microstructure was shown to develop a mixed fcc-hcp structure with cumulative straining (Figure 3), with both stacking-fault (SF) and nanotwins. The evolution with strain and grain size reduction of this dual fcc-hcp Co microstructure was also determined by X-ray diffraction. Figure 6 shows the XRD patterns obtained after the BM + SPS bottom-up process and after ECAP-B $\mathrm{C} / 1$ and ECAP- $\mathrm{B}_{C} / 4$. It appeared that the hcp phase was formed already after the BM + SPS bottom-up process. The volume fraction of the hcp phase increased to some extent, at the expense of the fcc phase, with the top-down ECAP- $\mathrm{B}_{\mathrm{C}}$ process of one to four passes.

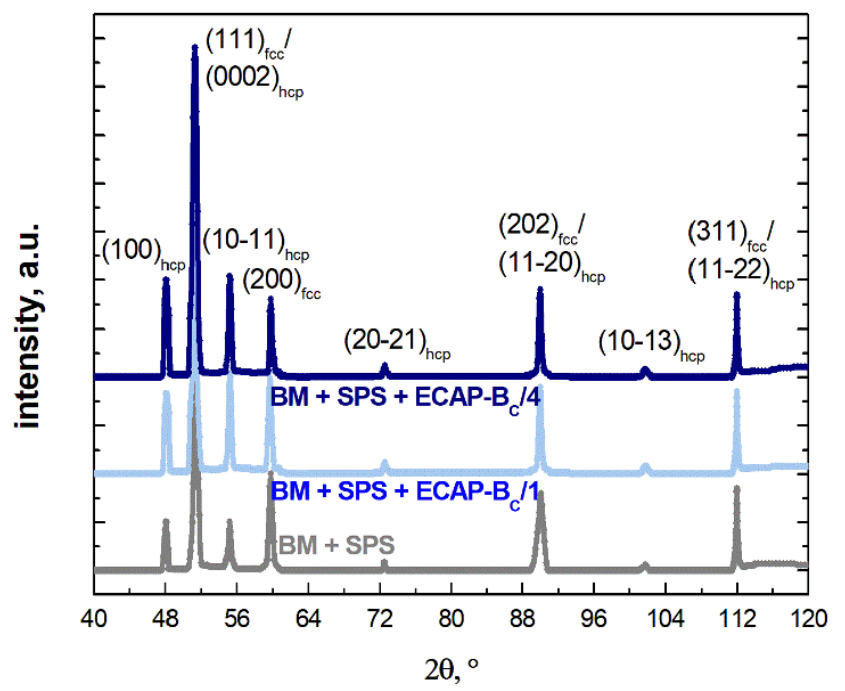

Figure 6. XRD patterns of BM + SPS (bottom-up process), BM + SPS + ECAP-B $/ 1$, and BM + SPS + ECAP-B ${ }_{C} / 4$ (top-down process). The 15-0806 (for fcc-Co) and 5-0727 (for hcp Co) JCPOS SPDD Metals and Alloys reference datasheets were used.

It is well-known that twin boundaries are a particular case of grain boundary characterized by a low-index of coincidence (typically <3) [32]. Moreover, as the strain rise, it is expected that twin boundaries are likely to contribute in a way quite similar to grain boundaries. Thus, the newly 
introduced tangled dislocations within the matrix will tend to form pile-ups near a twinning boundary leading to stress concentration near the boundary. Since twinning forms at the early stages of plastic deformation, most of the slip activity and thus accommodation of plastic deformation by slip occurs in the matrix. Therefore, it is believed that twin boundaries and twin-slip interaction can provide with high strain hardening in the strained cobalt. In one respect, twin boundaries can be thought of either as impenetrable obstacles or as boundaries inducing formation of finer grain sizes by subdivision of grains.

In the case of polycrystals, when both grain and twin boundaries are present, the relative strength of these boundaries is lower than that of the grain boundaries. This is because dislocations can dissociate at twin boundaries, allowing them to penetrate the twinned region. On the other hand, especially in UFG and NC structures, it is well-known that tangled dislocations are induced to pile-up at grain boundaries under the action of the cumulative straining. Therefore, grain boundaries constitute stronger barriers than twin boundaries.

Then, as the grain size reduces, there is a combined effect of increasing hardening role of grain boundaries, which are increasing in volume fraction, compared with twin boundaries. This microstructure aspect is likely to contribute to explain the hardening effect in a mixed fcc/hcp structure of cobalt. At the same time, a balance of the tendency, on side, to local elastic increment, due to the grain size reduction, and to the other side, to its reduction due to the slight increment of the twinned structures and hcp phase.

Beside these microstructure aspects, a further aspect related to the constant trend of $E_{\mathrm{r}}$ with cumulative ECAP straining refers to the grain size limit to the tip radius of curvature. In fact, as the mean grain size reduces to a NC level, the Co grained structure starts to be comparable to the nanoindenter Berkovich tip radius, which was of $120 \mathrm{~nm}$. Thence, the typical free path of the dislocations becomes shorter, due to the barrier effect of the surrounding nanometric grain boundaries.

\section{Conclusions}

$\mathrm{BM}+\mathrm{SPS}$ and following ECAP processes were applied to commercially pure cobalt. This constitutes a promising and quite reliable bottom-up and top-down grain-refining process in terms of (i) powder compaction, (ii) microstructure grain refining, (iii) mechanical response.

i. The bulk cobalt porosity was maintained quite low during the bottom-up process (BM + SPS), to be eventually further reduced to a minimum of $1.6 \%$, after $E C A P-B_{C}$ four passes;

ii. It resulted that grained structure was reduced to a UFG range after BM + SPS, and to NC range after ECAP-B $\mathrm{B}_{C} / 4$, as it finally reached $25 \mathrm{~nm}$, starting from $\sim 2 \mu \mathrm{m}$ cobalt powders (that is an almost 1/1000 grain reduction);

iii. The hardness, $H$, greatly increased after BM + SPS, and slightly under ECAP straining. Correspondingly, the reduced elastic modulus, $E_{\mathrm{r}}$, slightly reduced after BM + SPS and remained essentially constant under ECAP. The constant $E_{\mathrm{r}}$ with ECAP cumulative straining was attributed to the concurrent effect of grain size reduction and presence of twins and hcp phase.

Acknowledgments: This work was performed within the European Community Horizon 2020 Programme, COST Action CA15102 Solutions for Critical Raw Materials under Extreme Conditions (CRM_EXTREME). This research received no external funding. The author wishes to acknowledge A. Di Cristoforo for his help on TEM sample preparation and XRD measurements.

Conflicts of Interest: The author declares no conflict of interest.

\section{References}

1. Gleiter, H. Nanocrystalline materials. Progr. Mater. Sci. 1989, 33, 223-315. [CrossRef]

2. Kumar, K.S.; Van Swygenhoven, H.; Suresh, S. Mechanical behavior of nanocrystalline metals and alloys. Acta Mater. 2003, 51, 5743-5774. [CrossRef] 
3. Horita, Z.; Furukawa, M.; Nemoto, M.; Barnes, A.J.; Langdon, T.G. Superplastic forming at high strain rates after severe plastic deformation. Acta Mater. 2000, 48, 3633-3640. [CrossRef]

4. Lasio, B.; Torre, F.; Orrù, R.; Cao, G.; Cabibbo, M.; Delogu, F. Fabrication of Cu-graphite metal matrix composites by ball milling and spark plasma sintering. Mater. Letters 2018, 230, 199-202. [CrossRef]

5. Langdon, T.G. The principles of grain refinement in equal-channel angular pressing. Mater. Sci. Eng. A 2007, 462,3-11. [CrossRef]

6. Wetscher, F.; Vorhauer, A.; Pippan, R. Strain hardening during high pressure torsion deformation. Mater. Sci. Eng. A 2005, 410, 213-216. [CrossRef]

7. Saito, Y.; Utsumomiya, H.; Tsui, T.Y.; Sakai, T. Strain-induced grain refinement of cobalt during surface mechanical attrition treatment. Acta Mater. 1999, 47, 579-583. [CrossRef]

8. Wu, X.; Tao, N.; Hong, Y.; Liu, G.; Xu, B.; Lu, J.; Lu, K. Strain-induced grain refinement of cobalt during surface mechanical attrition treatment. Acta Mater. 2005, 53, 681-691. [CrossRef]

9. Abdul-Latif, A.; Dirras, G.F.; Ramtani, S.; Hocini, A. A new concept for producing ultrafine-grained metallic structures via an intermediate strain rate: Experiments and modeling. Int. J. Mech. Sci. 2009, 51, 797-806. [CrossRef]

10. Erb, U. Electrodeposited nanocrystals: Synthesis, properties and industrial applications. Nanostruct. Mater. 1998, 6, 533-538. [CrossRef]

11. Koch, C.C. Optimization of strength and ductility in nanocrystalline and ultrafine grained metals. Scipta Mater. 2003, 49, 657-662. [CrossRef]

12. Fellah, F.; Schoenstein, F.; Dakhlaoui-Omrani, A.; Chérif, S.M.; Dirras, G.; Jouini, N. Nanostructured cobalt powders synthesised by polyol process and consolidated by spark plasma sintering: Microstructure and mechanical properties. Mater. Character. 2012, 69, 1-8. [CrossRef]

13. Wen, C.S.; Huang, B.X.; Chen, Z.; Rong, Y.H. Martensite and its reverse transformation in nanocrystalline bulk Co. Mater. Sci. Eng. A 2006, 438, 420-426. [CrossRef]

14. Kitakami, O.; Sato, H.; Shimada, Y.; Sato, F.; Tanaka, M. Size effect on the crystal phase of cobalt fine particles. Phys. Rev. B 1997, 56, 13849. [CrossRef]

15. Valiev, R.Z.; Langdon, T.G. Principles of equal-channel angular pressing as a processing tool for grain refinement. Progr. Mater. Sci. 2006, 51, 881-981. [CrossRef]

16. Cabibbo, M. Microstructure strengthening mechanisms in different equal channel angular pressed aluminum alloys. Mater. Sci. Eng. A 2013, 560, 413-432. [CrossRef]

17. Cabibbo, M.; Santecchia, E.; Mengucci, P.; Bellezze, T.; Viceré, A. The role of cryogenic dipping prior to ECAP in the microstructure, secondary-phase precipitation, mechanical properties and corrosion resistance of AA6012 (Al-Mg-Si-Pb). Mater. Sci. Eng. A 2018, 716, 107-119. [CrossRef]

18. Cabibbo, M.; Blum, W.; Evangelista, E.; Kassner, M.E.; Meyers, M.A. Transmission electron microscopy study of strain-induced low- and high-angle boundary development in equal-channel angular-pressed commercially pure aluminum. Metal. Mater. Trans. A 2008, 39, 181-189. [CrossRef]

19. Liu, F.; Yuan, H.; Yin, J.; Wang, J.T. Influence of stacking fault energy and temperature on microstructures and mechanical properties of fcc pure metals processed by equal-channel angular pressing. Mater. Sci. Eng. A 2016, 662, 578-587. [CrossRef]

20. Zhu, Y.T.; Lowe, T.C. Observations and issues on mechanisms of grain refinement during ECAP process. Mater. Sci. Eng. A 2000, 291, 46-53. [CrossRef]

21. Cabibbo, M. A TEM Kikuchi pattern study of ECAP AA1200 via routes A, C, BC. Mater. Charact. 2010, 61, 613-625. [CrossRef]

22. Oliver, W.C.; Pharr, G.M. An improved technique for determining hardness and elastic modulus using load and displacement sensing indentation experiments. J. Mater. Res. 1992, 7, 1564-1583. [CrossRef]

23. Fisher-Cripps, A.C. A review of analysis methods for sub-micron indentation testing. Vacuum 2000, 58, 569-585. [CrossRef]

24. Cabibbo, M.; Ricci, P.; Cecchini, R.; Rymuza, Z.; Sullivan, J.; Dub, S.; Cohen, S. An international round-robin calibration protocol for nanoindentation measurements. Micron 2012, 43, 215-222. [CrossRef] [PubMed]

25. Edalati, K.; Toh, S.; Arita, M.; Watanabe, M.; Horita, Z. High-pressure torsion of pure cobalt: hcp-fcc phase transformations and twinning during severe plastic deformation. Appl. Phys. Lett. 2013, 102, 181902. [CrossRef]

26. Karimpoor, A.A.; Erb, U. Mechanical properties of nanocrystalline cobalt. Phys. Stat. Sol. 2006, 203, 1265-1270. [CrossRef] 
27. Sort, J.; Zhilyaev, A.; Zielinska, M.; Nogués, J.; Suriňach, S.; Thibault, J.; Barò, M.D. Microstructural effects and large microhardness in cobalt processed by high pressure torsion consolidation of ball milled powders. Acta Mater. 2003, 51, 6385-6393. [CrossRef]

28. Hitzenberger, C.; Karnthaler, H.P.; Korner, A. Electron microscopy of H.C.P. cobalt at various temperatures. Acta Metall. 1985, 33, 1293-1305. [CrossRef]

29. Betteridge, W. The properties of metallic cobalt. Progr. Mater. Sci. 1980, 24, 51-142. [CrossRef]

30. Kalidindi, S.R. Incorporation of deformation twinning in crystal plasticity models. J. Mech. Phys. Solid. 1998, 46, 267-290. [CrossRef]

31. Pond, R.C.; Serra, A.; Bacon, D.J. Dislocations in interfaces in the h.c.p. metals-II. Mechanisms of defect mobility under stress. Acta Mater. 1999, 47, 1441-1453. [CrossRef]

32. Karaman, L.; Sehitoglu, H.; Beaudoin, A.J.; Chumlyakov, Y.I.; Maier, H.J.; Tomé, C.N. Modeling the deformation behavior of Hadfield steel single and polycrystals due to twinning and slip. Acta Mater. 2000, 48, 2031-2047. [CrossRef]

33. Ren, F.; Zhu, W.W.; Chu, K.J. Fabrication and evaluation of bulk nanostructured cobalt intended for dental and orthopedic implants. J. Mech. Behav. Bioned. Mater. 2017, 68, 115-123. [CrossRef] [PubMed]

34. Karimpoor, A.A.; Erb, U.; Aust, K.T.; Palumbo, G. High strength nanocrystalline cobalt with high tensile ductility. Scripta Mater. 2003, 49, 651-656. [CrossRef]

35. Barry, A.H.; Dirras, G.; Schoenstein, F.; Tétard, F.; Jouini, N. Microstructure and mechanical properties of bulk highly faulted fcc/hcp nanostructured cobalt microstructures. Mater. Charact. 2014, 91, 26-33. [CrossRef]

(C) 2018 by the author. Licensee MDPI, Basel, Switzerland. This article is an open access article distributed under the terms and conditions of the Creative Commons Attribution (CC BY) license (http://creativecommons.org/licenses/by/4.0/). 